\title{
RESPONSABILIDAD POR DAÑO AMBIENTAL, ANÁLISIS COMPARADO CHILE-COSTA RICA*
}

\section{LIABILITY FOR ENVIRONMENTAL DAMAGE; CHILE-COSTA RICA, A COMPARATIVE ANALYSIS}

\section{Ezio Costa Cordella**}

\begin{abstract}
RESUMEN: El presente artículo realiza un análisis comparado de los sistemas de responsabilidad ambiental de Chile y Costa Rica, particularmente de dos instituciones; la existencia o inexistencia de un sistema especial de responsabilidad ambiental, considerando para ello como variables: la existencia de una ley y acción especial, así como de otras especificidades y los Tribunales Ambientales de cada sistema en sus configuraciones básicas. A continuación, se analizan las semejanzas y diferencias entre ambos sistemas.
\end{abstract}

Palabras claves: daño ambiental, responsabilidad, medioambiente, reparación, tribunales ambientales.
ABSTRACT: This article undertakes a comparative analysis of the environmental liability systems of Chile and Costa Rica, specifically of two institutions; he existence or nonexistence of a special system of environmental liability, taking into account the following as variables: the existence of a law and special action, as well as of other specificities and the Environmental Courts of each system in their basic configurations. Then, we analyze the similarities and differences between both systems.

Keyzords: environmental harm, liability, environment, reparation, environmental courts.,

* Artículo recibido el 8 de julio de 2017 y aceptado para su publicación en 25 de octubre de 2017.

** ORCID: 0000-0003-3928-862. Abogado, Universidad de Chile. Dirección electrónica: ecosta@derecho.uchile.cl. Agradezco la ayuda de María Victoria Galleguillos y los interesantes comentarios de Mario Peña Chacón.

Boletín Mexicano de Derecho Comparado, nueva serie, año XLX, núm. 152, mayo-agosto de 2018, pp. 477-504.

Esta obra está bajo una Licencia Creative Commons Atribución-NoComercial-SinDerivar 4.0 Internacional, IIJ-UNAM. 
SUMARIO: I. Introducción. II. Selección del tópico y de los sistemas legales. III. Importancia de los sistemas de responsabilidad por daño ambiental. IV. Instituciones y contexto de la responsabilidad ambiental en Chile y Costa Rica. V. Análisis de semejanzas y diferencias entre los sistemas de Chile y Costa Rica. VI. Conclusiones: los problemas complejos requieren soluciones complejas.

\section{INTRODUCGIÓN}

Resulta interesante analizar los sistemas de responsabilidad por daño ambiental, en cuanto a ellos, por una parte, funcionan como una de las herramientas de política pública para la protección del medio ambiente y, por otra, representan un desafío tanto para el derecho civil como para el derecho público en términos institucionales. En este sentido, sabemos que la manera en que las legislaciones pueden establecer responsabilidad ambiental es variada y el presente trabajo se centrará en estudiar aquella que las respectivas leyes de bases - o generales - de medio ambiente de Chile y Costa Rica han privilegiado.

La pregunta que se hace este trabajo es sobre las similitudes que los sistemas de responsabilidad ambiental pueden tener, en contextos de existencia de tribunales ambientales. La hipótesis inicial es que, frente a la existencia de dichos tribunales, podría existir cierta uniformidad en los sistemas de responsabilidad. Esas semejanzas podrían deberse a la existencia de organismos similares.

Se pretende con esto, y especialmente con el estudio de las semejanzas y diferencias entre los sistemas, develar ciertas lógicas que subyacen a dichos sistemas y cuáles podrían ser sus consecuencias. En especial resultará interesante hacer una distinción entre la responsabilidad civil y la responsabilidad administrativa o sancionadora en materia ambiental, pues como veremos las leyes de bases de ambos países se jugaron por soluciones diversas en este sentido, sin perjuicio de que ellas se hayan creado en momentos similares y obedeciendo, en parte, a precursores semejantes.

Este trabajo se enmarca en la lógica comparativa de derecho privado y sigue la metodología propuesta por Danneman. Nos hacemos parte al mismo tiempo, de la crítica que él esboza al derecho comparado, en cuanto a que la disciplina comparada tiende a poner de mayor relieve las

Esta obra está bajo una Licencia Creative Commons

Atribución-NoComercial-SinDerivar 4.0 Internacional, IIJ-UNAM.

Boletín Mexicano de Derecho Comparado, núm. 152, pp. 477-504. 
similitudes que las diferencias. ${ }^{1}$ La metodología de Dannemann consta de cuatro etapas debidamente diferenciadas. Una primera se centra en la selección del tópico respecto del cual se hará la comparación y las bases para la misma. La segunda etapa consiste en la selección de los sistemas legales que se compararán y la justificación de dicha selección. En seguida, un tercer esfuerzo es el de describir las instituciones, reglas y contexto de los sistemas escogidos. Por último, se hace necesario el análisis propiamente tal, destacando y proponiendo explicaciones a las diferencias y semejanzas entre los sistemas que se estén comparando.

\section{SELECCIÓN DEL TÓPICO Y DE LOS SISTEMAS LEGALES}

El tópico elegido es la responsabilidad extracontractual, que, como señala Wagner, siempre ha sido uno de los temas que más ha atraído a los comparativistas. ${ }^{2}$ Dentro de la responsabilidad extracontractual, en específico nos centraremos en la responsabilidad por daño ambiental, la que tiene especificidades y complejidades respecto de la responsabilidad extracontractual general, siendo que es del caso que, como veremos, dichas variables incluso la llevan a estar en un área intermedia entre el derecho civil y el derecho administrativo.

En lo que se refiere al sistema legal chileno, la acción por daño ambiental está dividida en dos acciones diferentes, una que llamamos "de reparación ambiental", contenida en los artículos 51 y siguientes de la Ley 19.300 y otra que es propiamente de indemnización para los directamente afectados, para la cual se aplican las reglas generales, contenidas en el título XXXV del Libro IV del Código Civil. Esta división, previa a la Ley 20.600, que crea los Tribunales Ambientales, estaba principalmente relacionada con los legitimados activos para interponer la acción y el petitorio al tribunal, pero ambos eran conocidos por el juez de letras en lo civil del lugar donde se hubiera producido el daño, y en la práctica si era un directamente afectado quien interponía la acción, presentaba ambas de forma conjunta.

1 Dannemann, Gerhard, "Comparative Law: Study of Similarities or Differences?", en Reimann y Zimmerm (eds.), The Oxford Handbook of Comparative Law, Oxford, Oxford University Press, 2006, p. 384.

2 Wagner, Gerhard, "Comparative Tort Law", The Oxford Handbook of Comparative Law, Oxford, Oxford University Press, 2006, pp. 1003-1042.

Esta obra está bajo una Licencia Creative Commons Atribución-NoComercial-SinDerivar 4.0 Internacional, IIJ-UNAM. Boletín Mexicano de Derecho Comparado, núm. 152, pp. 477-504. 
La Ley 20.600 en su artículo 46 modificó lo anterior y le dio a los Tribunales Ambientales la competencia para conocer las acciones de reparación ambiental, mientras que creó un procedimiento especial para las acciones de indemnización de perjuicios, manteniendo la competencia para conocer de ellas en los Juzgados de Letras en lo civil. No encontramos ninguna explicación razonable para esta división, pareciendo que la misma es en realidad una de las barreras de acceso a la justicia que se incluyeron en la creación de los tribunales ambientales. ${ }^{3}$

Sin perjuicio de lo señalado, en materia ambiental una especificidad de Chile es la existencia de Tribunales Ambientales, cuestión que lo hace estar entre los pocos países que tienen esta judicatura especializada, siendo que en América Latina, los únicos otros países que tienen este tipo de tribunales son El Salvador y Costa Rica. ${ }^{4}$ Ese solo hecho ya hace interesante la comparación entre estos países para buscar las diferencias y semejanzas en lo que se refiere a sus sistemas de reparación por daño ambiental. La comparación; sin embargo, se realiza sólo entre Chile y Costa Rica, para profundizar mejor en el análisis, y tomando en cuenta que Costa Rica es un país con un contexto ambiental avanzado, del cual se pueden extraer mejores experiencias.

Así, por ejemplo, se puede desprender del hecho de que este país ocupe el primer lugar a nivel latinoamericano en el "Environmental Performance Index" (EPI), elaborado por el Centro de Derecho y Política Ambiental de la Universidad de Yale. ${ }^{5}$ El EPI rankea a los países en base a su capacidad de proteger la salud y los ecosistemas. En su versión 2016, Costa Rica está en el número 42 del ranking y en primer lugar latinoamericano, mientras que Chile está en el número 52 ocupando el sexto lugar a nivel regional. ${ }^{6}$ Si bien no es el derecho ambiental, ni menos el estatuto de responsabilidad ambiental lo que determina dichas posiciones, si es

3 Afirmamos esto en el entendido de que unificar las acciones de reparación e indemnización importaría un mayor incentivo para las víctimas de daño, de perseguir la referida reparación, generándose el mismo incentivo para operadores jurídicos que podrían trabajar con dichas víctimas. Al separarse la competencia de ambos estatutos se produce, por lo tanto, un desincentivo a dichas acciones y con ello una barrera de acceso a la justicia.

4 Si bien existe también un Tribunal Ambiental en Chiapas, México, éste no ha sido implementado a la fecha.

5 Véase http://epi.yale.edu/reports/2016-report (fecha de consulta: 5 de enero de 2016).

6 Véase http://epi.yale.edu/sites/default/files/2016EPI_Full_Report_opt.pdf, (fecha de consulta: 5 de enero de 2016).

Esta obra está bajo una Licencia Creative Commons

Atribución-NoComercial-SinDerivar 4.0 Internacional, IIJ-UNAM.

Boletín Mexicano de Derecho Comparado, núm. 152, pp. 477-504. 
evidente que estos elementos influyen en la posición en que los países terminan en el ranking. Sostenemos, entonces, que es muy probable que el derecho ambiental chileno tenga cosas que aprender del derecho ambiental costarricense.

Pero, además, la semejanza cultural producto de la coincidencia territorial-regional es otro punto que hace interesante la comparación entre estos dos sistemas. Ambos son sistemas que originalmente se conciben como de derecho civil o continental y que en materia ambiental han evolucionado en el tiempo de manera más o menos sincrónica a la luz de los avances internacionales en la materia, y con fuerte influencia de los organismos y la comunidad internacional, como precursor de las primeras normas ambientales.

En referencia a la comparación entre países latinoamericanos, es interesante considerar lo que ha señalado Carpizo, en torno a que hay factores aglutinadores en América Latina como son: $a$ ) una historia que tiene aspectos comunes, $b$ ) poseer una herencia cultural similar, $c$ ) el idioma español que se habla en la mayoría de los países, d) la idea de unidad del pueblo latinoamericano, e) una tradición jurídico-política similar con influencias francesas, españolas y norteamericanas, $f$ ) la raza mestiza, $g$ ) la existencia de problemas que nos son comunes, $h$ ) la fuerza de la unión entre los países de la región, i) los intentos de colaboración e integración económica. ${ }^{7} \mathrm{Si}$ bien algunas de esas variables no nos parecen relevantes - especialmente la referencia racial-, de todas formas participamos de la idea de que existe una similitud entre países latinoamericanos que es beneficiosa para la comparación.

\section{IMPORTANCIA DE LOS SISTEMAS DE RESPONSABILIDAD POR DAÑO AMBIENTAL}

Si bien en general reconocemos que el derecho ambiental está basado principalmente en sus acciones preventivas y precautorias, y por lo tanto en el accionar de la administración, no es menos cierto que este enfoque está balanceado por el de la responsabilidad en materia ambiental, que entrega una solución jurídica a los daños ya producidos.

7 Carpizo, Jorge, "Derecho constitucional latinoamericano", Anuario de Derechos Humanos, nueva época, t. 1, vol. 7, 2006, pp. 268-278.

Esta obra está bajo una Licencia Creative Commons Atribución-NoComercial-SinDerivar 4.0 Internacional, IIJ-UNAM. Boletín Mexicano de Derecho Comparado, núm. 152, pp. 477-504. 
En este sentido, entre los principios de la Declaración de Río, se encuentra uno que se refiere a la responsabilidad ambiental en específico, estableciendo:

PRINCIPIO 13: Los Estados deberán desarrollar la legislación nacional relativa a la responsabilidad y la indemnización respecto de las víctimas de la contaminación y otros daños ambientales. Los Estados deberán cooperar asimismo de manera expedita y más decidida en la elaboración de nuevas leyes internacionales sobre responsabilidad e indemnización por los efectos adversos de los daños ambientales causados por las actividades realizadas dentro de su jurisdicción, o bajo su control, en zonas situadas fuera de su jurisdicción.

Así, el principio de responsabilidad aparece como una especificación del principio general de responsabilidad, entendida como "...un juicio normativo que consiste en imputar a una persona una obligación reparatoria en razón del daño que ha causado a otra persona. ${ }^{8}$

Esta interpretación, sin embargo, no alcanza a abarcar plenamente a la responsabilidad ambiental, la cual se ha entendido como no sólo la reparación de las víctimas del daño en específico, sino que más ampliamente como la reparación del medio ambiente en sí mismo, entendiendo la naturaleza colectiva de este bien jurídico.

Sobre esto, Esteve Pardo ha señalado que si bien la responsabilidad por daño ambiental se desarrolló al alero de la responsabilidad civil, tiene como características peculiares: a) la magnitud que pueden alcanzar los daños causados; $b$ ) los problemas de causalidad, y $c$ ) la existencia de daños patrimoniales y propiamente ambientales. Tanto en la primera como en la última característica, el autor hace referencia a lo que nos hemos referido anteriormente, en el sentido de que más allá del daño y la reparación que se pueda hacer a personas afectadas, existe un daño específico, al medio ambiente en sí mismo, que debe ser reparado en los casos de responsabilidad ambiental. ${ }^{9}$

A mayor abundamiento, la responsabilidad en materia ambiental ha seguido paralelamente caminos civiles y administrativos. En ese sentido,

8 Barros Bourie, Enrique, Tratado de responsabilidad extracontractual, Santiago, Editorial Jurídica de Chile, 2014, p. 15.

9 Esteve Pardo, José, Derecho del medio ambiente, 3a. ed., Madrid, Marcial Pons, 2014, pp. 91-95.

Esta obra está bajo una Licencia Creative Commons

Atribución-NoComercial-SinDerivar 4.0 Internacional, IIJ-UNAM.

Boletín Mexicano de Derecho Comparado, núm. 152, pp. 477-504. 
Lozano reconoce la doble distinción que podemos hacer respecto de la responsabilidad por daño ambiental. Primero, esa responsabilidad puede ser administrativa o civil, dando a entender la autora que en el caso español la responsabilidad civil es residual y opera en caso de no existir responsabilidad administrativa. La segunda distinción se debe realizar una vez que ya nos encontramos frente a la responsabilidad civil, donde podríamos estar ante responsabilidad por culpa o responsabilidad objetiva. ${ }^{10}$

Además, en la lógica preventiva del derecho ambiental, el sistema de responsabilidad debería funcionar también como un desincentivo a la producción del daño. En esa línea, Banfi no duda en calificar a la responsabilidad ambiental como un instrumento utilizado por la política pública para el control de las actividades que pueden ocasionar impactos al medio ambiente. Además, el autor es crítico del rol que el derecho civil puede jugar en la protección ambiental, refiriéndose a ella en términos que "la responsabilidad civil no proporciona elementos de juicio para determinar la entidad de cada impacto ambiental, para comparar los bienes jurídicos en conflicto y para adoptar una posición que considere los probables costos y beneficios sociales de las opciones en juego". ${ }^{11}$ En esta misma línea, Barros ha señalado que "Este conjunto de razones [principalmente el carácter público del medio ambiente] conduce a que el derecho privado no sea el medio más eficaz para definir los estándares ambientales; en verdad, no hay camino alternativo a la regulación por la autoridad". ${ }^{12}$

Todo lo anterior dice relación con la especialidad de la responsabilidad ambiental, a propósito del bien jurídico que es tutelado por este sistema de responsabilidad. En efecto, no sólo estamos en presencia de un asunto meramente privado en que se esté protegiendo el patrimonio de las personas, sino que además se está protegiendo el medio ambiente en sí mismo, que es un bien jurídico colectivo y cuyo daño produce un interés difuso. ${ }^{13}$

10 Lozano Cutanda, Blanca, Derecho ambiental administrativo, 10a. ed., Madrid, Dykinson, 2009, p. 277.

11 Banfi, Cristián, "De la responsabilidad civil como instrumento de protección ambiental", Revista de Derecho Ambiental, Chile, núm. 2, 2004, p. 23.

12 Barros Bourie, Enrique, Tratado de responsabilidad extracontractual, Santiago, Editorial Jurídica de Chile, 2014, pp. 787 y 788.

13 En este sentido, véase Yarza, Fernando, "El llamado derecho al medio ambiente: un desafío a la teoría de los derechos fundamentales", Revista Española de Derecho Constitucional, Madrid, núm. 94, 2012, pp.153-179. 


\section{INSTITUCIONES Y CONTEXTO DE LA RESPONSABILIDAD AMBIENTAL EN CHILE Y COSTA RiGA}

Para efectos de la descripción de las instituciones relevantes para esta comparación de una manera efectiva, nos centraremos exclusivamente en dos instituciones. En primer lugar, la existencia o inexistencia de un sistema especial de responsabilidad ambiental, considerando para ello como variables: la consagración en una ley especial, la existencia de una acción especial y la existencia de otras especificidades. En segundo lugar, se analizará a los Tribunales Ambientales de cada sistema en sus configuraciones básicas, en búsqueda de semejanzas y diferencias. Todo lo anterior se hará cuidando de comparar fuentes similares, por lo que se tendrán a la vista los instrumentos normativos de cada uno de los países, así como jurisprudencia y doctrina relevante.

\section{Acciones por daño ambiental: normas especiales}

\section{A. Chile y el doble estatuto civil}

Como ya se señaló, la Ley 19.300, sobre Bases Generales del Medio Ambiente, consagra en Chile un sistema de acciones por daño ambiental que reviste especificidades en relación con el sistema corriente de responsabilidad extracontractual. Entre dichas especificidades contamos al menos con:

1) Concepto de daño: la norma de la significancia está contenida en el artículo 2o., letra e) de la Ley 19.300, que define al daño ambiental como: "toda pérdida, disminución, detrimento o menoscabo significativo inferido al medio ambiente o a uno o más de sus componentes". Vale decir que el concepto de daño ambiental se refiere al daño sobre el objeto llamado "medio ambiente" y no sobre una persona en particular, cuestión que ya constituye una variación importante en relación a la responsabilidad extracontractual.

2) Legitimación activa: conjuntamente con cualquier persona que haya sido directamente afectada, la ley entrega, en su artículo 54, la legitimación activa al Estado, que puede actuar a través del Consejo de Defensa del Estado, y asimismo a las municipalidades, cuando el daño se produce 
en el ámbito de su territorio. Incluso impone una obligación a las municipalidades de justificar su no-actuación, en caso de ser compelida a hacerlo por parte de cualquier vecino. Sobre quiénes son las personas legitimadas para accionar en base a ser directamente afectada, el segundo Tribunal Ambiental de Santiago se ha pronunciado señalando que:

Que, la tesis del "entorno adyacente" permite una interpretación útil y finalista de los artículos citados, pues sin asimilar la acción de reparación ambiental con una acción popular - "porque no corresponde a cualquiera del pueblo" (ibidem) - , permite entender el requisito de haber sufrido un daño o perjuicio como uno diferente del exigido en la acción indemnizatoria general. Entonces, las personas naturales o jurídicas, públicas o privadas, que no han experimentado un detrimento en su persona o patrimonio, eventualmente gozan de legitimación activa — sólo para la acción de reparación del medio ambiente, no para la indemnización de perjuicios-, si habitan o realizan sus actividades en el entorno adyacente supuestamente dañado. Lo que sea adyacente o circundante será inevitablemente un problema casuístico, pues resulta inconveniente definir ex ante qué se entenderá por adyacente en todos y cada uno de los casos. ${ }^{14}$

3) Presunción de culpa: la Ley 19.300 contempla en su artículo 52 una norma de presunción de culpa específica para el daño ambiental, que establece relación con el incumplimiento de normas ambientales, de manera que se presume la culpa de un agente cuando éste haya infringido

...normas de calidad ambiental, a las normas de emisiones, a los planes de prevención o de descontaminación, a las regulaciones especiales para los casos de emergencia ambiental o a las normas sobre protección, preservación o conservación ambientales, establecidas en la presente ley o en otras disposiciones legales o reglamentarias.

4) Sistema de acciones: como ya se explicó en el inicio de este trabajo, la Ley 19.300 y la Ley 20.600 han establecido un sistema de acciones de responsabilidad extracontractual que contempla dos acciones distintas para los casos de daño ambiental, una que sólo puede tener por objetivo la reparación del medio ambiente dañado y otra que persigue la indemnización de perjuicios.

14 Segundo Tribunal Ambiental, rol D-2-2013, considerando undécimo. 
5) Prescripción: el artículo 63 de la Ley 19.300 establece un plazo especial de prescripción de las acciones, que es de cinco años desde que se produce la manifestación evidente del daño.

\section{B. Costa Rica, responsabilidad administrativo-sancionadora}

En el caso de Costa Rica, la ley general de medio ambiente, Ley 7554, crea un sistema completamente distinto de acciones por daño ambiental, pues en efecto no establece un sistema contencioso del tipo del derecho civil, como el de la ley chilena, sino que opta por un procedimiento administrativo que se lleva ante el Tribunal Ambiental, pero donde es este mismo organismo el que actúa como investigador del asunto, siendo por lo tanto un procedimiento inquisitivo. Así las cosas, el procedimiento se inicia por una denuncia y continúa con la notificación al denunciado y una audiencia, la que puede ser precedida por inspecciones del tribunal. ${ }^{15} \mathrm{En}$ la práctica, se vuelve un sistema menos útil, pues el Tribunal Ambiental termina emitiendo una resolución que no tiene caracteres de cosa juzgada y que es revisable por la judicatura, a instancias que el nombre "Tribunal" pareciera no coincidir con la realidad del organismo administrativo.

El régimen costarricense de responsabilidad ambiental se encuentra regulado por diversos cuerpos normativos, entre ellos la Constitución Política de Costa Rica, la Ley Orgánica del Ambiente (número 7554/1995), la Ley de Biodiversidad (número 7788/1998), el Código Procesal Contencioso Administrativo y el Código Civil. La regulación del daño ambiental tiene a su vez determinadas características que la distinguen de la normativa aplicable a la responsabilidad extracontractual común del derecho civil. Entre estas características diferenciadoras encontramos:

1) Concepto de daño: La Ley Orgánica del Ambiente caracteriza al daño ambiental en el artículo 2o. titulado "Principios", dispositivo en el que se señala:

El daño al ambiente constituye un delito de carácter social, pues afecta las bases de la existencia de la sociedad; económico, porque atenta contra las

15 Peña Chacón, Mario, Daño responsabilidad y reparación ambiental, México, 2005, pp. 35-37, disponible en: http://cmsdata.iucn.org/downloads/cel10_penachacon03.pdf(fecha de consulta: 5 de enero de 2017).

Esta obra está bajo una Licencia Creative Commons

Atribución-NoComercial-SinDerivar 4.0 Internacional, IIJ-UNAM.

Boletín Mexicano de Derecho Comparado, núm. 152, pp. 477-504. 
materias y los recursos indispensables para las actividades productivas; cultural, en tanto pone en peligro la forma de vida de las comunidades, y ético, porque atenta contra la existencia misma de las generaciones presentes y futuras.

A su vez, el mismo artículo indica que "Quien contamine el ambiente o le ocasione daño será responsable, conforme lo establezcan las leyes de la República y los convenios internacionales vigentes".

2) Legitimación Activa Especial: El artículo 50, inciso segundo, de la Constitución de Costa Rica indica que "Toda persona tiene derecho a un ambiente sano y ecológicamente equilibrado. Por ello está legitimada para denunciar los actos que infrinjan ese derecho y para reclamar la reparación del daño causado". En materia de biodiversidad se contempla una norma específica de legitimación activa en la ley de biodiversidad, así su artículo 105 titulado "Acción popular" establece que: "Toda persona estará legitimada para accionar en sede administrativa o jurisdiccional, en defensa y protección de la biodiversidad". A su vez, como se verá parte del procedimiento de daño ambiental es ventilado en sede administrativa, y por ello en este sede al no existir una norma especial en la ley orgánica del ambiente se utilizaran los criterios del código procesal contencioso administrativo. La jurisprudencia, considerando el texto constitucional, ha establecido una acción popular en esta materia. Al respecto, la sentencia 00675 expediente 02-000682-0163-CA de la primera sala de la Corte señala:

Cualquier persona que alegue estar afectada por un daño ambiental pertenece a la parte material titular del interés difuso y estará legitimada para ser parte activa en el proceso judicial que se inicie en protección del ambiente. De acuerdo con el parámetro constitucional, producido un daño ambiental, en cualquiera de sus dos vertientes, se concede acción para obtener la reparación del ambiente, lo que no obsta al ejercicio de la acción indemnizatoria. Para lo primero debe deducirse la "acción ambiental" - recurso de amparo o vía ordinaria - para lo segundo la "acción indemnizatoria" — ejecución de sentencia o vía ordinaria-.

3) Sistema de acciones: Están contempladas entre los artículos 103 al 112 de la Ley número 7554/1995, Orgánica del Medio Ambiente, que regulan al Tribunal Ambiental Administrativo. De acuerdo a los artículos 
107 y 108 la vía de ingreso al tribunal es por medio de una denuncia. El artículo 111 regula la competencia del Tribunal Ambiental Administrativo (TAA) y establece en su letra c) que será competencia del tribunal "Establecer, en vía administrativa, las indemnizaciones que puedan originarse en relación con los daños producidos por violaciones de la legislación tutelar del ambiente y los recursos naturales". Es decir, el TAA puede otorgar indemnizaciones pecuniarias. La ley costarricense también establece, en la regulación de la Secretaría Técnica Nacional Ambiental -órgano desconcentrado del Ministerio de Ambiente y Energía - que este organismo tiene por función según el artículo 84 de la ley “c) Atender e investigar las denuncias que se le presenten en lo relativo a la degeneración o al daño ambiental". En cuanto a las reparaciones al medio ambiente destaca que en Costa Rica existe una metodología para la evaluación económica de daños ambientales, creada por el Instituto de Políticas para Sostenibilidad y el Sistema Nacional de Áreas de Conservación del Ministerio de Energía y Ambiente. El estudio señala tener por objetivo "el desarrollo de una estructura metodológica para valorar ecológica y económicamente los daños ambientales causados por distintas actividades económicas". ${ }^{16}$ Del estudio se destaca la evaluación de económica tanto de los daños físicos como sociales del medio ambiente.

4) Título de Imputación de Responsabilidad: No existe una norma general que se refiera al carácter objetivo (estricto) o subjetivo de la responsabilidad ambiental, ni una presunción como en el caso chileno. Sin embargo, en sentencia de casación de la Corte Suprema de Costa Rica del 2000, Sala Constitucional, voto 200-1669, no se requirió de norma expresa para aplicar la responsabilidad objetiva en un caso de contaminación. En dicha sentencia se señaló:

Se trata de un nuevo concepto de responsabilidad donde lo que priva es el criterio objetivo sobre el subjetivo, puesto que para su surgimiento es irrelevante si se actuó o no con culpa; basta con que el daño haya sido efectivamente ocasionado, para que de inmediato surja la consecuente responsabilidad. Así las cosas, en muchas ocasiones no es posible determinar, ni al culpable, ni la norma legal infringida, pues en la mayoría de los casos el daño es producto de una omisión, pero ciertamente se perjudica a terceras perso-

16 Véase http://wrere.inbio.ac.cr/estrategia/Estudio_2004/Paginas/PDF/Ambiente/IFVEDA. $p d f$ (fecha de consulta: 5 de enero de 2017).

Esta obra está bajo una Licencia Creative Commons

Atribución-NoComercial-SinDerivar 4.0 Internacional, IIJ-UNAM.

Boletín Mexicano de Derecho Comparado, núm. 152, pp. 477-504. 
nas o Estados, las o los que necesariamente son objetivo de indemnización. Dentro de este contexto es que debe entenderse el contenido del artículo 11 de la Ley Orgánica del Ambiente [sic].

5) Prescripción: La norma general en materia de prescripción en el derecho de Costa Rica se encuentra en el artículo 868 del Código Civil el cual señala: "Todo derecho y su correspondiente acción se prescriben a los diez años. El plazo para reclamar daños y perjuicios a personas menores de edad empezará a correr a partir de que la persona afectada haya cumplido la mayoría de edad". Ahora bien, tratándose de una solicitud de indemnización a reparación al Estado, el plazo se encuentra establecido en la Ley General de Administración Pública, la cual señala que: "El derecho a reclamar la indemnización a la Administración prescribirá en cuatro años, contados a partir del hecho que motiva la responsabilidad. El derecho a reclamar la indemnización contra los servidores públicos prescribirá en cuatro años después que se tenga conocimiento del hecho dañoso”. Peña, en un análisis de la jurisprudencia de la Corte Suprema de Costa Rica, concluye que cuando el daño ambiental afecta bienes públicos la acción es imprescriptible mientras que si afecta intereses o derechos subjetivos individuales es prescriptible. ${ }^{17}$ Dentro de las sentencias aludidas para fundamentar esta interpretación, el profesor señala el Voto Constitucional número 6898-97 de la Sala Constitucional de la Corte Suprema:

...el derecho a la salud deriva directamente del derecho a la vida y ni si quiera su propio titular puede renunciarlo, mientras que el de vivir en un medio ambiente equilibrado (ordinal 50 de la Constitución) es un derecho social, por su naturaleza irrenunciable conforme al artículo 74 ibídem. Por el contrario la caducidad a que se refiere la citada de la ley de esta jurisdicción es aplicable solamente a aquellos derechos puramente patrimoniales y cuya violación puede ser válidamente consentida. De esta suerte, sería necesario tomar en cuenta también que la lesión argüida (afectación de la salud física y mental de los vecinos por motivo de la operación de la referida terminar de autobuses) sería de efecto continuado, en la medida que se repite día con día, de donde tampoco cabria alegato la preclusión del derecho.

17 Peña Chacón, Mario, "Daño ambiental y prescripción", Revista fudicial, Costa Rica, núm. 109, septiembre de 2013. 


\section{Tribunales Ambientales}

\section{A. Chile: el modelo contencioso-administrativo}

En Chile, los Tribunales Ambientales (TA) fueron establecidos mediante la Ley 20.600, en 2012. Se definen como "órganos jurisdiccionales especiales" y se sujetan a la superintendencia de la Corte Suprema.

Las características fundamentales de los TA, de acuerdo a HantkeDomas, son el hecho de ser independientes orgánica y económicamente; ser especiales en el conocimiento de sus causas y en la experticia de sus ministros, y cumplir un rol jurisdiccional. ${ }^{18}$ De las características antes señaladas, una que es común a los TA y a otros Tribunales Administrativos Especiales, como los hemos descrito, es el hecho de que son creados para abordar un problema que es calificado como complejo desde un punto de vista "técnico". ${ }^{19}$ Es con base en esa creencia que se produce una de sus más relevantes características, que es el hecho de estar compuesto por tres ministros, de los cuales dos son abogados especialistas del área, y un tercero es un "licenciado en ciencias".

La competencia de los TA es en principio acotada a aquellas materias que señala el artículo 17 de su ley, sin perjuicio de que otras leyes pudieran darles más competencias. De acuerdo al artículo 17, los TA son competentes para conocer principalmente de las reclamaciones que se hagan contra actos administrativos, ya sea relacionados con el Sistema de Evaluación de Impacto Ambiental, con las resoluciones de la Superintendencia del Medio Ambiente, o con normas dictadas por el Ministerio de Medio Ambiente, así como otros actos de carácter ambiental. Fuera de sus competencias referidas al control de la Administración del Estado, el numeral 2) del artículo 17 dispone que deberá:

Conocer de las demandas para obtener la reparación del medio ambiente dañado, en conformidad con lo dispuesto en el Título III de la ley $\mathrm{N}^{\circ}$

18 Hantke-Domas, Michael, "Características de los nuevos tribunales ambientales: jurisdicción y especialidad”, en Ferrada, Juan Carlos, Bermúdez, Jorge y Pinilla, Francisco (eds.), La nueva justicia ambiental, Thomson Reuters, 2015, pp. 57 y 58.

19 Costa Cordella, Ezio, "Los tribunales administrativos especiales en Chile", Revista de Derecho, Chile, vol. XXVII, núm.1, 2014, p.156.

Esta obra está bajo una Licencia Creative Commons

Atribución-NoComercial-SinDerivar 4.0 Internacional, IIJ-UNAM.

Boletín Mexicano de Derecho Comparado, núm. 152, pp. 477-504. 
19.300. Será competente para conocer de estos asuntos el Tribunal Ambiental del lugar en que se haya originado el hecho que causa el daño, o el de cualquier lugar en que el daño se haya producido, a elección del afectado.

Como nota Bermúdez, "la creación de los TTAA responde a la necesidad de controlar los actos provenientes de la Administración Pública Ambiental, en particular la SMA, y de facilitar el acceso a la justicia ambiental." ${ }^{20}$ Luego, agrega que en el análisis de sus competencias, se puede desprender que es un tribunal contencioso administrativo y que lo excepcional es que conozca cuestiones ambientales propiamente tales, que es el caso de las acciones por daño ambiental o la facultad de autorización de medidas provisionales. ${ }^{21}$

Ahora bien, como ya se señaló, los TA sólo pueden conocer de esta demanda en cuanto a la reparación del medio ambiente y no a la posible indemnización que de ello se derive. Para conocer de este asunto, y como dispone la Ley 19.300, se requiere de una demanda por daño ambiental incoada por un afectado directo, el municipio donde se produjo el daño o el Estado.

\section{B. Costa Rica: el Tribunal Administrativo Ambiental como inquisidor}

El Tribunal Ambiental Administrativo (TAA) de Costa Rica fue creado en 1995 en su Ley Orgánica del Ambiente, vale decir que es el Tribunal Ambiental más antiguo de la región. Sin perjuicio de ello, el TAA tiene características muy distintivas en relación a los TA chilenos, partiendo por el hecho de que, como nota Burdyshaw, este organismo es de carácter más bien administrativo. ${ }^{22} \mathrm{Al}$ igual que los TA chilenos, ellos buscan ser una instancia especializada en materia ambiental y fueron creados con ese objeto. Sin embargo, se incorporaron para esos efectos miembros provenientes de otras disciplinas, siendo sus jueces abogados con experiencia en materia ambiental.

20 Bermudez Soto, Jorge, Fundamentos de derecho ambiental, 2a. ed., Valparaiso, Ediciones Universidad Católica de Valparaíso, 2014. p. 519.

21 Idem.

22 Burdyshaw, Cassandra, “QQué puede aprender Chile de la experiencia de otros tribunales ambientales en el mundo?", Fusticia Ambiental, núm. 4, 2012, pp. 93-120. 
El TAA tiene competencia, de acuerdo al artículo 111 de la Ley Orgánica del Ambiente, para:

a) Conocer y resolver, en sede administrativa, las denuncias establecidas contra todas las personas, públicas o privadas, por violaciones a la legislación tutelar del ambiente y los recursos naturales. b) Conocer, tramitar y resolver, de oficio o a instancia de parte, las denuncias referentes a comportamientos activos y omisos que violen o amenacen violar las normas de la legislación tutelar del ambiente y los recursos naturales. c) Establecer, en vía administrativa, las indemnizaciones que puedan originarse en relación con los daños producidos por violaciones de la legislación tutelar del ambiente y los recursos naturales.

De acuerdo a Burdyshaw, sin embargo, se ha considerado que la mayoría de las veces la sola multa no es suficiente, por lo que se practica algún tipo de reparación ambiental como obligación adicional, siendo especialmente complejo el asunto en cuanto no es claro el destino de los fondos de las "indemnizaciones". ${ }^{23}$

El TAA de Costa Rica, como puede verse, es un organismo administrativo que recibe y gestiona las denuncias por daño ambiental y luego sanciona en caso de que corresponda. Sus funciones son bastante diferentes de las de los TA chilenos, y podríamos incluso decir que reúne funciones que en nuestro sistema son propias de la Superintendencia de Medio Ambiente, con otras que son de los TA. Veremos más sobre el punto a la hora de hacer el análisis de la institución.

\section{ANÁLISIS DE SEMEJANZAS Y DIFERENCIAS ENTRE LOS SISTEMAS DE CHILE y COSTA RiCA}

\section{Existencia de un sistema de responsabilidad ambiental}

Hemos observado las principales características de los sistemas de responsabilidad por daño ambiental en Chile y Costa Rica, y salta a la vista que existen diferencias fundamentales entre ellos, incluso en algunas zonas que a primera vista parecerían similares y que son de las que gatillaron la elección de ambos países para la comparación. En esta fase final del análisis,

23 Ibidem, p. 111.

Esta obra está bajo una Licencia Creative Commons

Atribución-NoComercial-SinDerivar 4.0 Internacional, IIJ-UNAM.

Boletín Mexicano de Derecho Comparado, núm. 152, pp. 477-504. 
emprendemos la tarea de intentar explicar las diferencias y semejanzas entre los sistemas. ${ }^{24}$

La primera similitud que encontramos entre las leyes de bases del medio ambiente de ambos países tiene que ver con su creación, que coincide además con la creación de la rama y la legislación del asunto en la mayoría de los países latinoamericanos. Como señala Cabrera, en Latinoamérica y luego de la Declaración de Río (1992), el impacto de la Declaración de Estocolmo (1972) fue muy importante para modificar la normativa y las políticas ambientales. En especial, señala el autor, las leyes de bases o de marco del medio ambiente, como son la 19.300 de Chile, dictada en 1994, y 7554 de Costa Rica, del año 1995. ${ }^{25}$

El hecho de que ambos países hayan cumplido en poco tiempo con establecer sistemas que honraran sus obligaciones internacionales es consistente con lo que ha sido teorizado en la literatura bajo el concepto de "trasplantes legales". Esta realidad es recogida por Graziadei, quien construye una tipología de los principales motivos que provocarían estos trasplantes, señalando que ellos serían 1) la imposición por la fuerza; 2) el prestigio, y 3) la performance económica. ${ }^{26}$ Estos precursores de los trasplantes, sin embargo, no son únicos. Es del caso que, así como estas posibles causas, también se ha enfatizado el rol de lo que Haas llamó "comunidades epistémicas", ${ }^{27}$ y a las que Graziadei se refiere como "elites profesionales". ${ }^{28}$ Las comunidades epistémicas, señala Haas, son una red de profesionales que tiene cierta autoridad en una determinada área del conocimiento y que se reconoce con experticia en un determinado tema. Lo importante de esas redes es que comparten ciertas creencias fundamentales, ciertos acuerdos causales, nociones de validación e intersubjetividad para sopesar el conocimiento y objetivos de política pública similares con una gama de prácticas similares. ${ }^{29}$

24 Dannemann, Gerhard, op. cit., p. 416-418.

25 Cabrera Medaglia, Jorge, "El impacto de las declaraciones de Río y Estocolmo sobre la legislación y las políticas ambientales en américa latina", Revista de Ciencias furídicas, núm.100, 2003.

26 Graziadei, Michele, "Comparative Law as the Study of Transplants and Receptions", en Reimann, Mathias y Zimmermann, Reinhard (eds.), The Oxford Handbook of Comparative Law, Oxford, Oxford University Press, 2006, pp. 457-460.

27 Haas, Peter, "Epistemic Communities and International Policy Coordination", International Organization, vol. 46, núm. 1, winter, 1992, pp. 1-35.

28 Graziadei, op. cit. p. 474.

29 Haas, op. cit. p. 3. 
En lo que se refiere a esta similitud creemos que existen posibilidades de que haya habido una influencia de las comunidades epistémicas, por la fuerza que ellas tienen en relación con cuestiones ambientales. En efecto, a esto se ha referido el propio Haas, junto a Adler, dando como ejemplo de ello el caso de la contaminación por clorofluorocarbonos (GFGs), un tipo de contaminante especialmente agresivo con la capa de ozono y que fuera regulado en varios países a merced de estas comunidades, ya existentes antes de la Declaración de Río y que probablemente se fortalecieron con posterioridad. ${ }^{30}$ Lo anterior, por supuesto, sumado a la propia imposición, por prestigio, que la Declaración de Río en sí misma significa, en especial cuando además fue apoyada tanto por organismos como por la comunidad internacional.

Por último, entre los precursores habitualmente teorizados, es importante descartar la influencia de las negociaciones internacionales de Tratados de Libre Comercio (particularmente con el NAFTA), que en Chile efectivamente ha sido sindicada como un precursor fundamental para la creación de la Ley 19.300, ${ }^{31}$ pero que en el caso de Costa Rica no pareciera tener una influencia, cuando vemos que su Tratado de Libre Comercio con Estados Unidos es recién de 2004. ${ }^{32}$

\section{Carácter del sistema de responsabilidad ambiental en las leyes de base del medio ambiente}

Como ha sido posible observar en el presente trabajo, hemos agrupado bajo el concepto de "responsabilidad ambiental" a sistemas que son esencialmente distintos. Esto obedece a que el análisis comparado tomó como punto de partida las leyes de bases de medio ambiente de Chile y Costa Rica, para empezar a notar luego que cuando trataron el asunto de la responsabilidad ambiental, uno optó por una vía más cercana a la res-

30 Adler, Emanuel y Haas, Peter, "Las comunidades epistémicas, el orden mundial y la creación de un programa de investigación reflectivo", Relaciones Internacionales, núm. 12, 2009, UNAM, pp. 145-169.

31 Silva, E., "Contemporary Environmental Politics In Chile: The Struggle Over The Comprehensive Law”, Organization E̊ Environment, vol. 8, núm. 4, 1994, p. 323-343.

32 Véase http://wrwre.sice.oas.org/ctyindex/CRI/CRIagreements_s.asp (fecha de consulta: 5 de enero de 2017).

Esta obra está bajo una Licencia Creative Commons

Atribución-NoComercial-SinDerivar 4.0 Internacional, IIJ-UNAM.

Boletín Mexicano de Derecho Comparado, núm. 152, pp. 477-504. 
ponsabilidad extracontractual, y otro optó por una vía de responsabilidad administrativa o sancionadora.

En este punto es importante notar que Bermúdez clasifica la responsabilidad proveniente del daño ambiental en tres: 1) "ambiental" propiamente tal, que sería la que impone la reparación del medio ambiente; 2) "civil", que es la que se relaciona con las indemnizaciones para terceros afectados, y 3) "sancionadora", que es la que se relaciona con responder por los incumplimientos a deberes administrativos, provenientes de los instrumentos de gestión ambiental. ${ }^{33} \mathrm{Si}$ bien esta clasificación puede ser esclarecedora para algunos efectos, en el tratamiento que nosotros estamos dando a la comparación, lo que nos interesa develar es si la responsabilidad ambiental en sí misma, vale decir, la que obliga a la reparación del bien común medio ambiente, tiene un estatuto más bien civil o más bien administrativo.

Lo anterior, en un contexto en que ambos países crearon en tiempos similares su sistema de responsabilidad ambiental, el resultado fue distinto. En principio, las normas de responsabilidad ambiental en uno y otro país difieren principalmente en su carácter de administrativas o civiles. Mientras en Costa Rica se aprecia un carácter mucho más público de la responsabilidad ambiental, en Chile el sistema era en la Ley 19.300 eminentemente civil, y hoy podemos pensar que estamos frente un sistema mixto, pues por una parte existen normas administrativas relacionadas con el incumplimiento de las normas ambientales y por la otra se mantienen las normas civiles de responsabilidad ambiental, que se refieren tanto a la reparación del medio ambiente como a la indemnización de daños y perjuicios a privados.

A pesar de esta aparente duplicidad, es necesario tomar en cuenta que los estatutos de responsabilidad civil y administrativo son totalmente distintos y de hecho, como hemos visto en el caso de la responsabilidad enmarcada en un procedimiento administrativo sancionatorio, derivan en sanciones que la administración puede aplicar por el incumplimiento a instrumentos de gestión ambiental.

De la observación de las potestades de la Superintendencia del Medio Ambiente (SMA) de Chile, se desprende que ellas están enfocadas en la

33 Bermúdez Soto, Jorge, op. cit., p. 389. 
fiscalización y control del cumplimiento de los instrumentos de gestión ambiental y que el daño es sólo una variable para determinar la gravedad de la sanción. Así está considerado en el artículo 36 de la Ley 20.417 (Orgánica de la Superintendencia del Medio Ambiente), que gradúa las infracciones en leves, graves y gravísimas. La única facultad que está efectivamente vinculada con el daño ambiental es la de los planes de reparación, que son un instrumento incorporado por la Ley 20.417 al estatuto de responsabilidad ambiental y que permiten al autor de daño ambiental presentar un programa voluntario de reparación ante la SMA y con ello inhibir la acción de responsabilidad ambiental. Este instrumento, sin embargo, no ha sido utilizado desde su implementación y la literatura especializada lo considera un fracaso. ${ }^{34}$

Con todo, difícilmente podemos considerar que efectivamente exista un doble estatuto de responsabilidad ambiental, siendo que ella, a pesar de la reforma de 2010 y la creación de la SMA, sigue funcionando bajo la lógica del derecho civil.

El carácter de la responsabilidad por daño ambiental no es baladí, pues el solo hecho de reconocer que es una de las maneras que tiene el Estado para asegurar la protección ambiental, la pone en un estado de política pública que debiera propender al cumplimiento de ciertos objetivos, cuestión que no siempre se consigue. Así, por ejemplo, Brañes lista los factores que a su juicio hacen ineficiente la legislación ambiental, señalando que ellos serían:

...la falta de presencia de la idea del desarrollo sostenible en el sistema jurídico en general y, especialmente, en la legislación económica: 2) la carencia de instrumentos apropiados para su aplicación, en particular de aquellos de naturaleza preventiva; 3 ) la falta de consideración de las cuestiones sociales y naturales involucradas en los asuntos ambientales; y 4) su heterogeneidad no sólo material sino también estructural. ${ }^{35}$

34 Dussaubat, Jean Paul, "Daño ambiental y el fracaso de la reparación voluntaria: diagnóstico y propuestas", Revista de Derecho Ambiental, año IV, núm. 6, 2016, pp. 178204.

35 Brañes Ballesteros, Raúl, "Los mecanismos para la aplicación del derecho para el desarrollo sostenible en América Latina", La fundación del derecho ambiental en América Latina, México, PNUMA, 2006, p.13.

Esta obra está bajo una Licencia Creative Commons

Atribución-NoComercial-SinDerivar 4.0 Internacional, IIJ-UNAM.

Boletín Mexicano de Derecho Comparado, núm. 152, pp. 477-504. 
De los factores anteriores, al menos tres están relacionados con el sistema de responsabilidad ambiental; en primer lugar, que los instrumentos de aplicación de la legislación sean apropiados y especialmente preventivos; en segundo, que ellos incorporen de alguna manera la idea de desarrollo sostenible, y por último, el hecho de que sean estructuralmente heterogéneos, cuestión relacionada con las estructuras jurídicas distintas en las que el problema se anida. El que la responsabilidad ambiental se juegue por un estatuto de base más bien civilista o más cercano al derecho administrativo modifica su carácter preventivo. Asimismo, el hecho de que se diseñe la responsabilidad ambiental de una manera muy estricta en un estatuto, probablemente, impacta en su dificultad para incorporar el desarrollo sustentable. Sobre la última variable sí tenemos una discrepancia, como se expresará más adelante, pues creemos que una solución mixta, y por lo tanto heterogénea, sí puede ser una buena respuesta cuando nos referimos al daño ambiental y sus múltiples posibilidades de manifestación.

Como veíamos anteriormente, los dos estatutos diferenciados de responsabilidad no pueden ser considerados como equivalentes, pues uno es principalmente de cumplimiento administrativo, éste es el que Corral llama "responsabilidad sancionatoria", ${ }^{36}$ y el otro, de responsabilidad civil, "aparece esencialmente vinculada al daño que sufre una o más personas individualizables, y al deber que tiene alguien de repararlo y compensarlo con medios equivalentes". ${ }^{37}$

Una pregunta interesante que surge a propósito de esto es cuál es el carácter de la responsabilidad ambiental en Chile. Delgado ha señalado que:

Lo importante - como destaca la doctrina especializada - es tener claro que el daño que se busca reparar no es el que sufren los particulares en su patrimonio, vida o salud, con ocasión de un daño ambiental, sino reparar el daño ambiental "puro", "público" o "colectivo". Si se contamina un río, la acción civil por daño ambiental busca su descontaminación, por ejemplo, dragándolo para sacar los metales pesados depositados en su fondo, y no la reparación económica por los daños causados al dueño de los vacu-

36 Corral Talciani, Hernán, Lecciones de responsabilidad civil extracontractual, 2a. ed., Santiago, Thomson Reuters, 2013. p. 14.

37 Ibidem, p. 16. 
nos que murieron por envenenamiento, o los niños que se intoxicaron al beber agua captada de ese río, o el camping que no recibió más clientes, etcétera. ${ }^{38}$

El sistema de responsabilidad ambiental en Chile, en lo que se refiere a la acción indemnizatoria y como señala Barros, "no ha introducido cambio alguno en el régimen general de responsabilidad civil". ${ }^{39}$ No sucede lo mismo con la acción de reparación, la que siendo compatible con la de indemnización y pudiendo tener objetivos similares, reconoce una titularidad ampliada para accionar y una causa de pedir que no es el mero interés individual, en vista que su única finalidad posible es la de reparación ambiental.

Siendo del caso que el sistema costarricense no estableció un estatuto especial de responsabilidad civil en materia ambiental, ello no ha obstado a que se enfrente este problema de naturaleza de la acción y las pretensiones en ella contenidas, cuando los tribunales conocen de acciones civiles por daño ambiental. Así, la Sala Primera ha señalado sobre el asunto que en lo relativo a daños irreversibles, debe estudiarse si corresponde una especie de "daño moral colectivo social", expresa en este sentido que:

Dentro de esta temática, de surgir la obligación de resarcir este tipo de menoscabo, no se configura una suma de porciones identificables; por el contrario, es una lesión general, que resulta aprehensible y experimentable, en donde el elemento afectado es comunitario o grupal, que llega a los sujetos individuales indivisiblemente, por la inserción en el conjunto. En vista de lo expuesto, se debe distinguir entre daños al ambiente y daños a través del ambiente. Este último se basa en la responsabilidad civil tradicional: daños personales, patrimoniales y económicos. El otro por el contrario, se refiere al daño ambiental per se. ${ }^{40}$

38 Delgado Schneider, Verónica, "La responsabilidad extracontractual por el daño ambiental causado en la construcción u operación de carreteras", Revista de Derecho de Valdivia, vol. XXV, núm.1, 2012, p. 49.

39 Barros Bourie, Enrique, Tratado de responsabilidad extracontractual, Santiago, Editorial Jurídica de Chile, 2014, p. 799.

40 Garita Navarro, José Roberto y Jiménez Sanabria, Santiago, "Acciones colectivas, difusas y populares para la defensa del ambiente", en Peña, Mario (ed.), El derecho al ambiente en la constitución política, alcances y límites, Costa Rica, Universidad de Costa Rica, 2016, p. 200.

Esta obra está bajo una Licencia Creative Commons

Atribución-NoComercial-SinDerivar 4.0 Internacional, IIJ-UNAM.

Boletín Mexicano de Derecho Comparado, núm. 152, pp. 477-504. 
La inexistencia de un sistema civil especial de responsabilidad, redunda en que no haya claridad sobre el destino que podría tener una potencial indemnización por el daño al medio ambiente en sí mismo; sin embargo, es interesante notar como la jurisprudencia reconoce la distinción existente entre la pretensión de una indemnización a un particular, y la de reparar el medio ambiente dañado o indemnizar por dicho daño. Esa diferencia es recogida también por la doctrina costarricense. ${ }^{41}$

Como lo han señalado Aguilar e Iza, además: "La reglamentación ambiental establece normas y procedimientos destinados a preservar el ambiente. En ausencia de un régimen de responsabilidad, el incumplimiento de las normas y procedimientos vigentes sólo puede entrañar una mera sanción de carácter administrativo o penal". ${ }^{42}$ Lo que los autores notan es importante, los estatutos civiles y administrativos sancionadores, así como también los penales, cumplen funciones diversas y por lo tanto en aras de la protección ambiental debieran complementarse.

De lo visto anteriormente es claro que ambos sistemas tienen sus propios problemas, en especial en el sistema costarricense se reclama la inexistencia de un estatuto especial de responsabilidad civil por daño ambiental, cuestión que entendemos como necesaria y útil, pero que nos pone en posición de preguntarnos si es ese un sistema que propenda de mejor manera a la protección del medio ambiente.

La primera respuesta, a la luz de la literatura antes citada, es que no parece el mejor sistema, pues los propios profesores de derecho civil consideran que el estatuto de responsabilidad por daño ambiental debiera ser más bien administrativo. Pero esto tiene que también estar vinculado a lo que Brañes ha detectado como causales de ineficiencia del derecho ambiental latinoamericano:

En ese sentido, nos parece claro que una de las razones más profundas de las insuficiencias de la gestión ambiental en la región tiene que ver con la manera cómo ha sido concebida. En efecto, muchas veces su cometido ha sido diseñado de una manera limitada, que no tiene en consideración las complejidades de los ecosistemas y las interrelaciones de sus componentes, así como las vinculaciones que existen entre el medio ambiente y el desarrollo. En

41 Idem.

42 Aguilar, Grethel e Iza, Alejandro, Derecho ambiental en Centroamérica, Gland, UICN, 2009, t. I, núm. 66, p. 115. 
consecuencia, las actividades de las administraciones ambientales se han reducido al tratamiento sectorial de algunos problemas ambientales, mediante soluciones que por otra parte no inciden en sus causas. ${ }^{43}$

La manera en que se concibe la gestión ambiental evidentemente impacta en su eficiencia, siendo del caso que los estatutos de derecho civil en materia ambiental son especialmente complicados. Para Brañes no sólo no ha habido ningún avance significativo en la materia, sino que además un "[P] roblema básico de la justicia es la reparación de daño ambiental, especialmente cuando este daño va más allá de la lesión de un interés individual". ${ }^{44}$ A dicha dificultad, se suman el problema de la legitimación activa, el régimen cautelar, el régimen de prueba, los alcances de la cosa juzgada civil y el impulso procesal de las partes. ${ }^{45}$ Como vemos, Brañes critica tanto al sistema de responsabilidad civil como al administrativo.

Entre los autores nacionales, a su vez, el sistema concebido como de responsabilidad civil ha sido criticado por sus escasos resultados. Así por ejemplo Bermúdez, quien a 20 años de la Ley 19.300 cree que los resultados no han sido satisfactorios y centra sus esperanzas en la posibilidad nueva de que sean los Tribunales Ambientales quienes conozcan de la acción, por una parte, y por otra al hecho de que existan los programas de cumplimiento ambiental en sede administrativa. ${ }^{46}$ Sobre este último asunto ha habido un mayor auge, aunque, como dijimos, ello no se relaciona directamente con el daño ambiental, pero sobre lo primero, la realidad nos muestra que, a 3 años de funcionamiento de los Tribunales Ambientales, se han presentado 55 demandas por daño ambiental ${ }^{47}$ de un total de 309 causas que han ingresado a los TA, entre reclamaciones, solicitudes y demandas. Vale decir, apenas un $17 \%$ de las causas que han sido conocidas por los TA.

En el sistema costarricense, el problema pareciera pasar por la falta de un estatuto civil. En el sistema chileno, existen ambos estatutos, pero

43 Brañes Ballesteros, Raúl, "Los mecanismos para la aplicación del derecho para el desarrollo sostenible en América Latina", cit., p.15.

44 Ibidem, p. 19.

45 Ibidem, pp. 21 y 22.

46 Bermúdez Soto, Jorge, op. cit., p. 444.

47 2o. TA: 32, 3er TA: 23. Entre ellas se cuentan dos demandas en el 3TA que fueron declaradas inadmisibles por no tener competencia.

Esta obra está bajo una Licencia Creative Commons

Atribución-NoComercial-SinDerivar 4.0 Internacional, IIJ-UNAM.

Boletín Mexicano de Derecho Comparado, núm. 152, pp. 477-504. 
el problema se vincula a la falta de conexión del estatuto sancionatorio con el daño ambiental en sí mismo, de suerte que parecería que no existe un estatuto sancionatorio per se en materia de daño ambiental, sino meramente un sistema sancionatorio relacionado con instrumentos de gestión ambiental. Si como señala Brañes, a los estatutos de responsabilidad les pena la falta de conexión con el medio ambiente, es evidente que en el caso chileno ello es más grave, como vimos.

\section{Dos modelos de Tribunales Ambientales}

En efecto y como vimos más arriba, el hecho de que ambos países tengan en su entramado normativo a Tribunales Ambientales pareciera, en primera instancia, una similitud que hace más posible comparar a sus sistemas, pero en realidad, en un análisis más detenido sobre el asunto, descubrimos que los tribunales en cada país son muy diferentes y que incluso dicha diferencia muestra una conceptualización del derecho ambiental en general y una en particular, que es profundamente diferente.

El TAA costarricense es sustancialmente distinto de los TA chilenos en general, y especialmente en materia de daño ambiental. El TAA recibe y gestiona denuncias por daño ambiental, cuestión que en Chile no está a cargo de ningún órgano específico. De acuerdo a Brañes: "La aplicación administrativa del derecho ambiental es una tarea que, tradicionalmente, se ha encargado a los organismos globales y/o sectoriales que integran la administración pública del medio ambiente, habitualmente por medio de unidades que cumplen solo esa función". ${ }^{48}$ En este sentido, Brañes compara la Procuraduría Ambiental del Distrito Federal con el Tribunal Ambiental Administrativo de Costa Rica, como organismos similares con posibilidad de sancionar, evidenciando que probablemente dicho organismo es más cercano en sus funciones a lo que sería nuestra Superintendencia del Medio Ambiente, con la salvedad de que el TAA está construido con el medio ambiente como base, y la SMA y los TA chilenos tienen como cimiento el sistema de instrumentos administrativos de gestión ambiental.

48 Brañes Ballesteros, Raúl, El acceso a la justicia ambiental en el Distrito Federal y la procuraduría ambiental y del ordenamiento territorial, México, Procuraduría Ambiental y del Ordenamiento Territorial del D. F., 2002, p. 130. 
Esto último es muy importante porque muestra una lógica subyacente totalmente diferente en el derecho ambiental chileno y el derecho ambiental costarricense. Así las cosas, en el sistema chileno no sólo los TA tienen mayoritariamente competencias que establecen relación con actos administrativos, sino que de la misma manera la SMA, órgano fiscalizador especializado en materia ambiental y que tiene amplias facultades de sanción, no cuenta con competencias para conocer del daño ambiental, ni siquiera para tratar denuncias sobre él. Por el contrario, sus competencias se fijaron en función de los instrumentos de gestión y por lo tanto pueden fiscalizar incumplimientos a Resoluciones de Calificación Ambiental o a proyectos que no posean dicha autorización, entre otras. A propósito de esas facultades fiscalizadoras, puede cursar sanciones por los incumplimientos que detecte y eventualmente podría aceptar un plan de reparación como sustituto de un procedimiento judicial, pero no puede iniciar acciones de reparación de daño ambiental por sí misma. En este cariz, no sólo es un sistema puramente de responsabilidad administrativo sancionador, sino que además protege al propio sistema administrativo en lugar del medio ambiente.

\section{CONCLUSIONES: LOS PROBLEMAS COMPLEJOS REQUIEREN SOLUGIONES COMPLEJAS}

El establecimiento de un sistema eficaz de reparación de los daños ocasionados al medio ambiente constituye un desafío para las lógicas tradicionales de la responsabilidad extracontractual. Lo anterior, debido a la particularidad del medio ambiente como bien jurídico afectado, a la existencia de una serie de intereses públicos comprometidos y al deber estatal de protección al medio ambiente, así como también a la exigencia de lidiar con daños irreparables, difusos y continuos.

En este escenario, Chile y Costa Rica comparten no sólo la creación de órganos especializados para abordar las particularidades de este régimen, sino que aparentemente ambos participan en la necesidad de crear un sistema que se diferencia del sistema general de responsabilidad, asegurando ello con la creación de una institucionalidad diversa. Sin embargo, el sistema costarricense pareciera ser más fiel a las singularidades del daño ambiental como también a la misma Declaración de Rio, que sirvió antecedente para la dictación de ambas normativas.

Esta obra está bajo una Licencia Creative Commons

Atribución-NoComercial-SinDerivar 4.0 Internacional, IIJ-UNAM.

Boletín Mexicano de Derecho Comparado, núm. 152, pp. 477-504. 
En efecto, el método inquisitivo, la denuncia y no la demanda como vía de ingreso, la extensión de la competencia y la amplitud de la legitimación activa hacen que la actuación del Tribunal Ambiental Administrativo sea potencialmente más efectiva y que el sistema de daños ambientales se distancie de forma relevante del sistema general de daños patrimoniales y extrapatrimoniales civiles. Este alejamiento es especialmente curioso dado que tal como fue visto, los autores costarricenses niegan un tratamiento especial del daño ambiental a nivel legislativo, lo que explicaría que dentro de su normativa no se comprenda una definición especial para el mismo.

Por otro lado, Chile, a pesar de contar con Tribunales Ambientales, tiene un régimen más moderado al momento de abordar las dificultades de la responsabilidad por daño ambiental, e incluso los instrumentos introducidos precisamente para facilitar la reparación ambiental, a saber los planes de reparación, no han tenido los resultados esperados. Lo anterior podría encontrar explicación en que el surgimiento de los TA y las modificaciones introducidas al sistema de responsabilidad ambiental por medio de la Ley 20.417 y de la Ley 20.600 no respondieron en absoluto a un consenso en torno a la necesidad de modificar el sistema de responsabilidad; muy por el contrario, se motivaron en un primer caso, por la existencia de un deficiente sistema de fiscalización, especialmente de resoluciones de calificación ambiental, ${ }^{49}$ y en el segundo principalmente con el objeto de ejercer vigilancia sobre la discrecionalidad administrativa otorgada a la SMA.

Lo anterior no significa que el sistema puramente sancionatorio administrativo de Costa Rica sea esencialmente mejor, o que el agrupamiento de las funciones de fiscalización y sanción en el TAA de dicho país sea institucionalmente más avanzado que el chileno. Sin embargo, la conexión existente entre la figura de daño ambiental y las potestades del TAA costarricense sí parecen superiores en la conceptualización, pues este organismo especializado efectivamente utiliza su especialización en materia ambiental y no es sólo un especialista en derecho administrativo e instrumentos de gestión, como parecerían ser los organismos ambientales chilenos y en especial la SMA y el TA. Sin embargo,

49 Biblioteca del Congreso Nacional, Historia de la Ley núm. 20.417, p. 13, disponible en: http://wwre.bcn.cl/obtienearchivo?id=recursoslegales/10221.3/3929/6/HL20417.pdf, (fecha de consulta: 5 enero de 2017). 
la práctica de esas potestades es un mundo distinto que corresponderá evaluar en su mérito.

El estudio comparado de los dos sistemas nos ha arrojado, de acuerdo a nuestras pretensiones, una serie de semejanzas y diferencias, las que creemos sirven para iluminar las complejidades que importa la responsabilidad por el daño ambiental, así como la necesidad de que ella sea abordada desde perspectivas diversas y en atención a los objetivos trazados por la política pública. Estos objetivos no pueden ser otros que no contemplen la mayor protección ambiental posible, y ello debiera ser tenido en cuenta.

Por último, el estudio ha descartado nuestra hipótesis inicial referida a las posibles semejanzas entre ambos sistemas a propósito de la existencia de Tribunales Ambientales. Por el contrario, la corroboración de que el diseño institucional de unos y otros tribunales es esencialmente diferente nos pone en una situación de grandes diferencias y en la que es imposible concluir la uniformidad que se pretendía. 